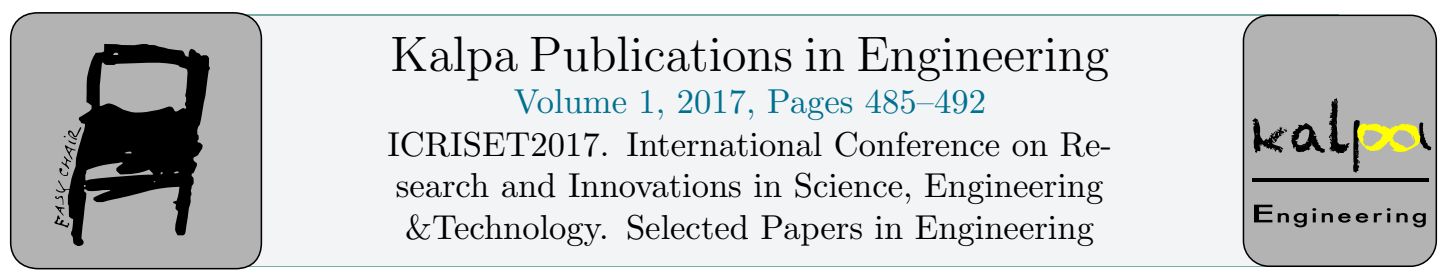

\title{
Multi-Objective Planning for Optimal Allocation of DG and RPC Units in Radial Distribution System Using Genetic Algorithm
}

\author{
Jaydeepsinh Sarvaiya $^{1}$ and Dr.Mahipalsinh Chudasama ${ }^{2}$ \\ ${ }^{1}$ Vishwakarma Government Engineering Colleg,Ahmedabad. \\ ${ }^{2}$ L.D Engineering College, Ahmedabad \\ jbs201182@gmail.com, mahipal175@gmail.com
}

\begin{abstract}
DG penetration is continuously increased across distribution network not only to reduce carbon emission, but also to enhance the performance of the distribution network. In a restructured environment any distribution utility need to address DG placement and sizing problem to find a cost effective solution for the specific investment. Most of the authors have attempted to solve the problem based on real power loss reduction across the network. Some authors consider voltage stability based analysis for increased loadability of network with real power loss. However, optimal reactive power compensation also need to be incorporated for a cost effective solution. In this paper an attempt has been made to address various types of DG and RPC units citing and sizing problem with multi-objectives consists real power loss reduction and VSI improvement. A new approach includes development of cost function to find cost-effective solution for distribution network. Evolutionary based Genetic Algorithm used to optimize the objective function. Proposed algorithm is tested on IEEE-33 bus radial distribution system.
\end{abstract}

\section{Introduction}

After restructuring of power system any distribution utility facilitates the cost effective solution for specific investment made for network upgradation. DG and RPC placement reveals technical befits make more concern to words for its placement and sizing across the distribution network. DG penetration is now days continuously increase makes passive distribution network to active and increase network complexity.

In previous literatures proposed different analytical and optimization based methods for finding out the optimal DER size and site. These methodologies were developed based on various objectives mostly includes active power loss minimization and voltage profile improvement. At the same time, 
investment cost of DG also includes by some authors. All these approaches having their own advantages and dis- advantages depend upon various constraints and system considerations. In [4] author has tried to introduce an analytical approach for an optimal DG placement solution with radial distribution network. In [5] a ' $2 / 3$ rule' is presented for a radial type distribution system with a uniformly distributed load. The procedure presented is uncomplicated but cannot directly be applied to a network with different types of load allocation. In [6] a loss sensitivity factor of different nods of network is calculated for the DG location to curtail the power loss without using any admittance matrix. In [7] power stability based analytical approach has been adopted to find out the impact of DG on network loss, node voltage and line voltage stability. In [8] author presented an analytical expression to find best capacity allocation and suggested methodology for finding the position of DG across the network. In [9] multi objective (criteria) includes economic benefit and maximum potential. $\operatorname{In}[10]$ the author presented an analytical terminology to find optimal solution includes the capacity and power factor of different types of DG with an single objective of loss minimization. In [11] the authors presented a new approach for maximizing potential advantage of optimally placed DERs to curtail losses, VAR losses in selected line.

Many authors also proposed different kind of optimization methods for finding out optimal solutions. In [12] G.A and PSO used to find optimal solution on distribution network. In [13] GA proposed to solve the problem with weighted multi objective criteria. PSO technique proposed in [14] for active and reactive power compensation by allocating different DGs across the distribution network. In [15] the authors proposed new methodology using GA to find size of fixed and switched shunt capacitor where capacitor positioning has been made to minimize losses and improve voltage w.r.t maximize annual saving.

Most of the research work only considers active power generation from PV for DG optimal analysis, but as there are many types of DGs available in the market, which can supply as well as absorb reactive power from the grid. In practice, in additional to the DGs, RPC devices are also present to feed up additional reactive demand so for more realistic solution in addition to various types of DG, RPC device need to include.

In this paper, an attempt has been made to address out DG as well as RPC sizing and citing problem across the distribution network. New methodology includes DG locations selection based on a voltage stability index. As per the index value, voltage sensitive buses are identified which are more critical to the voltage instability considering future load growth. After deciding DG location, size has been optimally selected using Genetic Algorithm. Wind turbine type DGs are selected to carry out analysis, which can also provide reactive power support to the grid. Looking to the additional reactive demand of the network Loss sensitivity factors are calculated of all different lines and according to its values, RPC locations are determined. Multi objective fitness function has been developed which includes loss minimization and cost minimization. The IEEE-33 bus distribution network has been taken to apply this methodology. This paper is subdivided into the following sections: section 2 presents problem formulation based on voltage stability and loss sensitivity factor. Section 3 describes the algorithm for DG as well as RPC allocation based on stability index and LSF. Section 4 includes results of the applied methodology for IEEE-33 bus distribution network.

\section{Problem formulation}

\subsection{Theoretical Analysis for calculation of voltage stability.}

A simple two bus system shown fig1, 


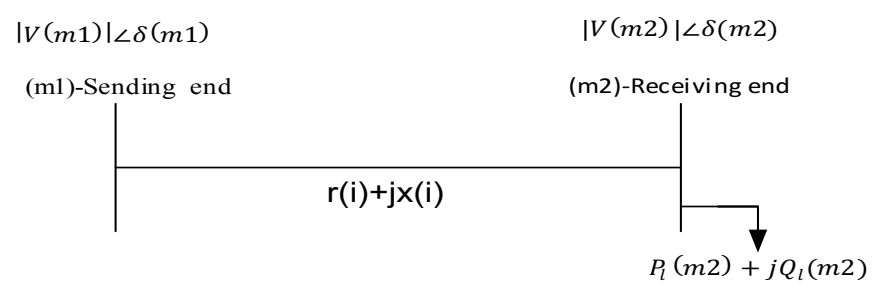

Figure 1 : Simple two bus network

The fundamental objective includes enhancement of the voltage level of the network to keep it within acceptable limit. Thus, the voltage at the load end can be enhanced by reducing voltage drop IZ component.

In this case, local real and reactive power support is provided by connecting DERs and RPC devices. Active and reactive losses depend upon line impedance, thus making them decisive factors for VSI analysis.

The concept behind identifying the nodes for proposed DG locations is based upon VSI developed by [7], which predict most critical buses of the system, which experience voltage instability issues considering future load growth.

For a two bus distribution network,

$$
\begin{gathered}
S_{l}=V_{r} I_{r}^{*} \\
S_{l}=P_{l}-j Q_{l} \\
\overrightarrow{V_{r}}=\overrightarrow{V_{s}}-\overrightarrow{I_{r} Z}
\end{gathered}
$$

Where $I_{r}$ is the current at receiving end $\left(\mathrm{m}_{2}\right)$

$$
\overrightarrow{I_{r}}=\frac{P_{l^{-}-j Q_{l}}}{V_{r}^{*}}
$$

Considering real and reactive power support at load end by injecting proper type of DG, (4) can be written as:

$$
\overrightarrow{I_{r}}=\frac{\left(P_{l}-P_{g}\right)-j\left(Q_{l}-Q_{g}\right)}{V_{r}^{*}}
$$

As for two bus network shown in fig (4),

$$
\overrightarrow{V\left(m_{2}\right)}=\overrightarrow{V\left(m_{1}\right)}-\overrightarrow{I Z}
$$

Substituting value of $\overrightarrow{I_{r}}$ from (5) in (6) and solving will give real part,

$$
P_{l}-P_{g}=\frac{\left|V_{s}\right|\left|V_{r}\right|}{|Z|} \cos \left(\varnothing-\delta_{s}+\delta_{r}\right)-\frac{\left|V_{r}\right|^{2}}{|Z|} \cos (\varnothing)
$$

Rearranging (7) gives a quadratic equation,

$$
\left|V_{r}\right|^{2}-\frac{\left|V_{S}\right|\left|V_{r}\right| \cos \left(\varnothing-\delta_{s}+\delta_{r}\right)}{\cos (\varnothing)}+\frac{Z\left(P_{l}-P_{g}\right)}{\cos (\varnothing)}=0
$$

For stable node voltages, (9) should have real roots, i.e. Discriminant $b^{2}-4 a c \geq 0$.

$$
\frac{V_{s}^{2} \cos ^{2}\left(\varnothing-\delta_{s}+\delta_{r}\right)}{\cos ^{2} \emptyset}-\frac{4 Z\left(P_{l}-P_{g}\right)}{\cos \emptyset} \geq 0
$$

The Voltage Stability Index as proposed by[8] evaluated by simplifying above equation(9), which gives the lines and the subsequent nods of network which are most critical to voltage collapse considering future load growth. 


\subsection{Theoretical Analysis for calculation of Loss sensitivity factor.}

Loss Sensitivity Factor (LSF) $[6,14]$ is evaluated to determine the candidate locations for the RPC placement. The computation of these candidate buses for RPC placement initially helps in reduction of the search space for the optimization problem. Consider a distribution line section with an impedance of $\mathrm{Rm}, \mathrm{m}+1+\mathrm{jXm}, \mathrm{m}+1$ and a load of $\mathrm{Pm}+1$,eff $+\mathrm{jQm}+1$,eff connected between $\mathrm{m}$ and $\mathrm{m}+1$ buses as shown in below Fig 2,

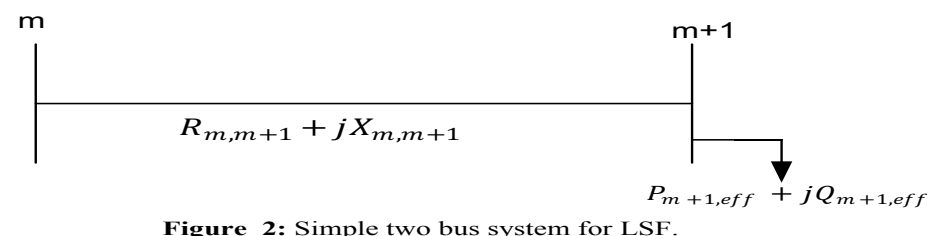

The LSFs can be evaluated for above network with the help of following equation,

$$
\frac{\partial P_{\text {Loss } m, m+1}}{\partial Q_{m+1, e f f}}=\frac{2 * Q_{m+1, e f f^{*} R_{m, m+1}}}{\left|V_{m+1}\right|^{2}}
$$

Using the above equation, LSFs are computed from the NR-load flows and values are arranged in descending order for all the lines of the given network. Eq. (10) is used to compute the candidate bus for RPC placement. LSFs decide the locations considered for RPC installation. From the sequence of LSFs the buses which have lower voltage $[\mathrm{v}<0.96 \mathrm{p}$.u] will select for RPC placement.

\subsection{Optimal sizing of DG and RPC on a Radial Network.}

Fig 4. Presents one line diagram of IEEE-33 bus radial distribution test network. After deciding the location of DG and RPC on distribution network, the next problem is to find the capacity because the improper size may be resulted in increase in losses and poor voltage profile. Genetic Algorithm is used to address sizing problem of DG and RPC in the most economical way. A multi objective fitness function developed to find out the optimal solution with satisfying all necessary power and voltage constraints.

As shown in the flow chart, Search starts with random variable values, in each iteration fitness function evaluate and GA's operator crossover, mutation and reproduction perform to find global optimal sizing for DG and RPC device. As it is iterative process final solution has been reached after meeting termination criteria.

Table 1 presents various algorithm specific parameters for the genetic algorithm. Termination criteria set for maximum nos of generation reached and maximum generation is set with sixty.

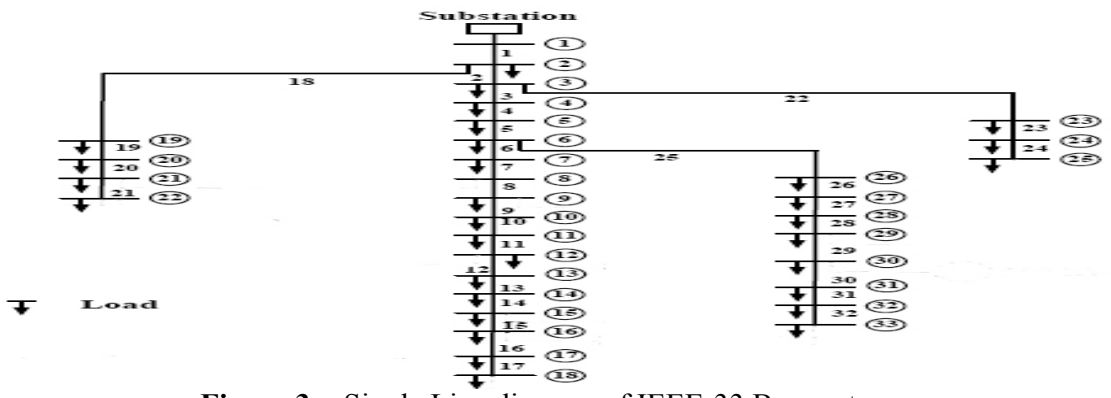

Figure 3: Single Line diagram of IEEE-33 Bus system. 


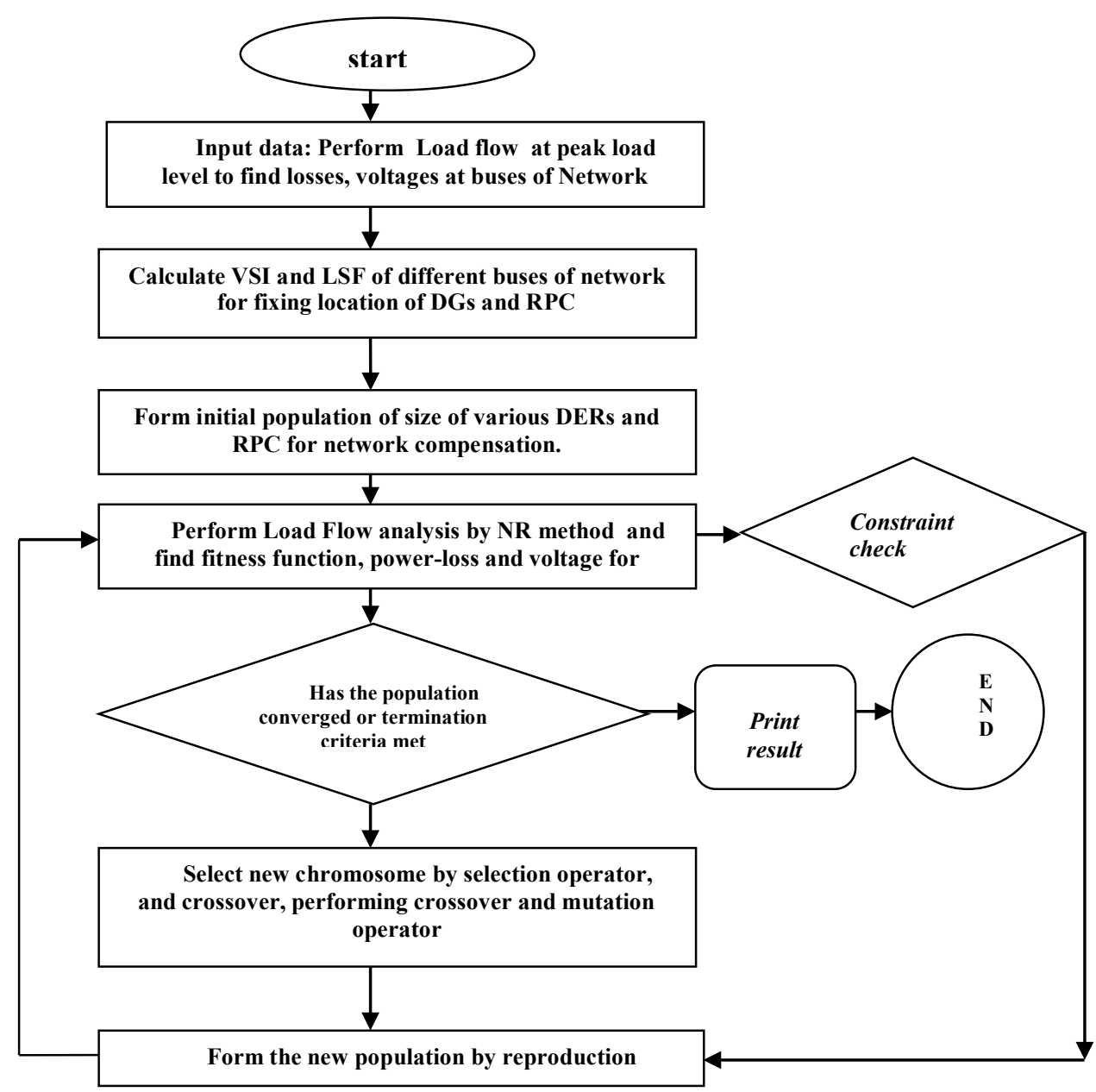

Figure 4: Proposed Algorithm for optimal sizing

\begin{tabular}{|c|c|c|c|c|c|}
\hline Sr.No & $\begin{array}{c}\text { Component of Genetic } \\
\text { Algorithm }\end{array}$ & Method/Value & Sr.No & $\begin{array}{c}\text { Component of Genetic } \\
\text { Algorithm }\end{array}$ & \multicolumn{2}{|c|}{ Method/Value } \\
\hline 1 & Crossover Probability & 0.95 & 8 & Objective function & Minimization \\
\hline 2 & Mutation Probability & 0.2 & 9 & Nos of Population & 100 \\
\hline 3 & No. of Population & 80 & & \multicolumn{2}{|c|}{ Bounds of variables } \\
\hline 4 & No of generation & 60 & 10 & Power constraint for DG & 0 to 0.005 P.U \\
\hline 5 & Termination Method & $\begin{array}{c}\text { Maximum } \\
\text { Generation }\end{array}$ & 11 & Q limit for DG & -0.004 to 0.004 \\
\hline 6 & Crossover Method & Arithmetic & 12 & $\begin{array}{c}\text { Reactive power limit for } \\
\text { RPC }\end{array}$ & 0 to 0.004 PU \\
\hline 7 & Mutation Method & Adaptive feasible & 13 & DG penetration limit & $45 \%$ \\
\hline
\end{tabular}

Table 1: Algorithm specific parameters value 


\section{Objective function}

Proposed Objective function (F) of the problem aimed to minimize the power loss in the system and maintained voltage magnitude of buses while minimizing total cost of investment behind DG and RPC devices. The multi objective function described as below,

$\operatorname{Min} F=k_{1} \times \frac{P_{\text {Loss }}}{P_{\text {Loss } 0}}+k_{2} \times \frac{\sum \cos _{D G}}{\operatorname{cost}_{D G} \max }+k_{3} \times \frac{\sum \operatorname{cost}_{R P C}}{\operatorname{cost}_{R P C} \max }$

$\mathrm{F}=$ Multi objective optimization function to be minimized. $k_{1}, k_{2}, k_{3}=$ Weighted factors.

$P_{\text {Loss }}=$ Power loss of network after DG and RPC placed. $P_{\text {Loss } 0}=$ Base case power loss without DG and RPC.

$\sum \operatorname{cost}_{D G}=$ Cost of investment of DG to be placed.cost ${ }_{D G}^{\max }=$ Maximum investment cost of DG with max. size.

$\sum \operatorname{cost}_{R P C}=$ Cost of investment of RPC to be placed.cost $\operatorname{RPC}_{\max }=$ Maximum investment cost of RPC w.r.t full size.

\section{Simulation results}

Proposed methodology has been tested on the IEEE-33 bus distribution network. A computer program was written in MATLAB R2014a and run on Intel i5-2430M CPU 2.4 GHZ PROCESSOR.

\subsection{DG placement based on VSI}

VSI values evaluated for Test system shown in Fig 5. Four most critical locations with the highest value of VSI consider for DG support. As per their VSI, bus no 7,23,24,29 buses are considered for DG placement. In this paper DG modeled to provide active as well as reactive power support to respective buses.

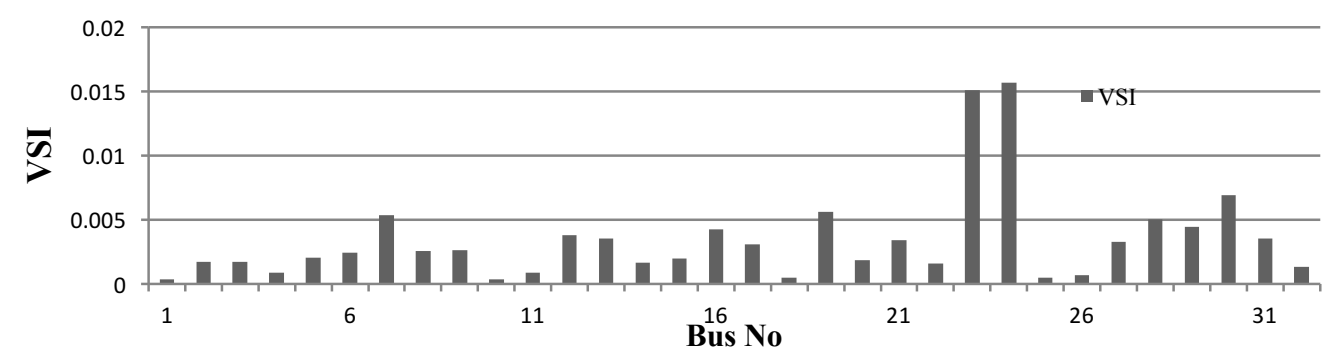

Figure 5: VSI values of IEEE-33 Buses.

\subsection{RPC placement based on LSF.}

L.S.F values have been calculated for all lines of the test distribution system. Table 2 shows Four buses consider for reactive power support by RPC as their having higher LSF with poor voltage profile.

\begin{tabular}{|c|c|c|c|c|}
\hline Bus & 05 & 12 & 9 & 8 \\
\hline LSF & 0.02200 & 0.012887 & 0.006369 & 0.0060 \\
\hline
\end{tabular}

Table 2: Bus locations with their LSF consider for RPC placement 


\subsection{Results of Genetic Algorithm.}

GA is used to give the optimal size of DERs and RPC devices on to the network. Fig 6 presents convergence graph of objective function for sixty nos of generation. The minimum objective function value after termination of GA is 0.6642 . Table 3 shows DG locations and their optimal size to facilitate active and reactive power support to the grid. Table 4 shows optimal RPC capacity and their respective locations

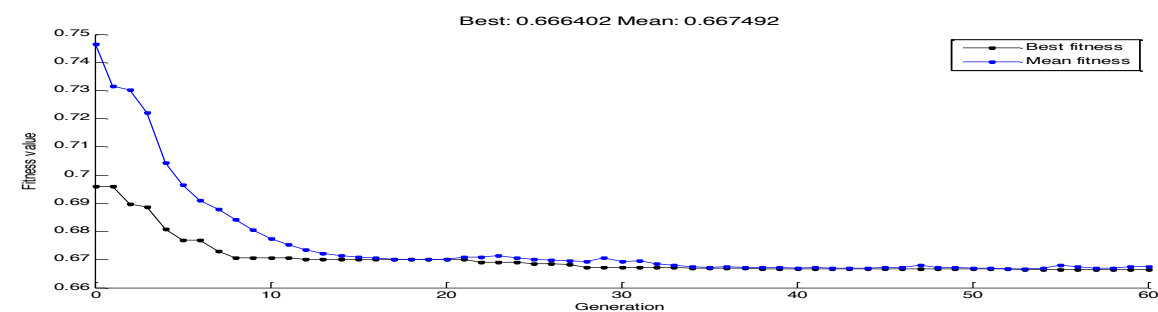

Figure 6 : Convergence graph of fitness function

\begin{tabular}{|c|c|c|c|c|}
\hline RPC locations & 05 & 12 & 9 & 8 \\
\hline Capacity in Kvar & 100 & 100 & 50 & 0 \\
\hline
\end{tabular}

\begin{tabular}{|c|c|c|c|c|}
\hline D.G locations & 7 & 23 & 24 & 29 \\
\hline Capacity in Kw & 395.4 & 207.5 & 201.9 & 397.7 \\
\hline Reactive Power by DG & 435.9 & 400.6 & 446.7 & 485.5 \\
\hline
\end{tabular}

TABLE 4: RPC locations and their capacity. T TBLE 3: DG active / reactive power support at weak buses

Fig 7 presents bus voltage profile comparison chart of the system before and after modification. Fig 8 presents reduction in active loss and reactive loss after DG and RPC placement across the distribution network.

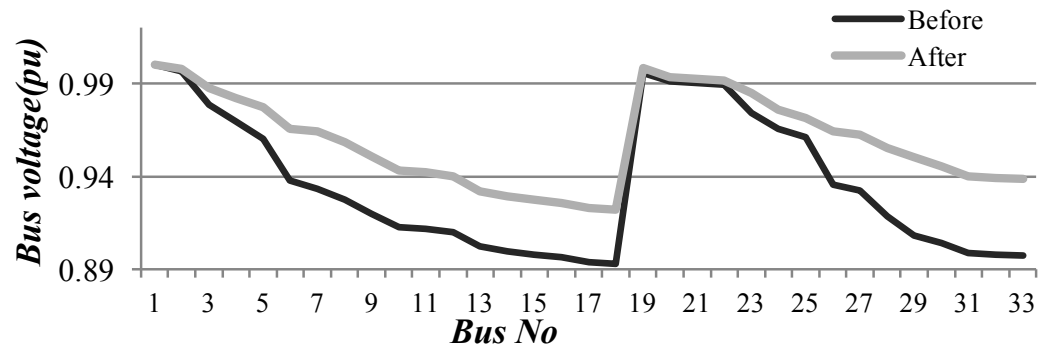

Figure 7 : Voltage profile comparison chart.

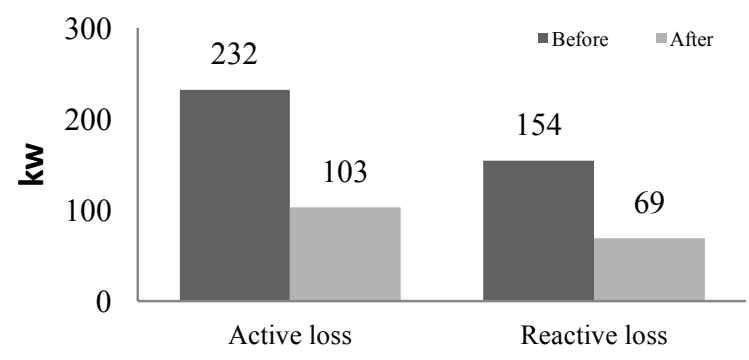

Figure 8: Active reactive loss comparison chart of IEEE-33 Bus system. 


\section{Conclusion}

Placement of DERs at appropriate locations with proper size is the major concern while interconnecting DERs with the utility grid. Since the RPC need to feed up additional reactive power of the network, this paper presents a new methodology, which combines optimal allocation of RPC device and DG for distribution network. VSI values are the key factor deciding critical buses and subsequent nodes, which are more prone to voltage collapse. Improper DG and RPC placement may lead to increase in losses and makes the things worse for existing network. From the above analysis of simulation results, indicate that the voltage profile has improved significantly and line losses reduced considerably thus, enhancing system, existing loadability with reduced burden of line losses and investment cost.

\section{References}

[1] G. Pepermans, J. Driesen, D. Haeseldonckx, R. Belmans, W. D’haeseleer, "Distributed generation: definition, benefits and issues," Energy Policy 33 (2005), pp. 787-798.

[2] M.M. Aman, G.B. Jasmon, H. Mokhlis, A.H.A. Bakar, "A new approach for optimum DG placement and sizing based on voltage stability maximization and minimization of power losses," Electrical Power and Energy Systems 34 (2012), pp. 66-74

[3] C. L. Masters, "Voltage rise the big issue when connecting embedded generation to long $11 \mathrm{kV}$ overhead lines," Power Engineering Journal, IEE February 2002.

[4] Caisheng Wang, M. Hashem Nehrir, "Analytical Approaches for Optimal Placement of Distributed Generation Sources in Power Systems," IEEE Transactions on Power Systems, Vol. 19, No. 4, November 2004, pp. 2068-76.

[5] H.L. Willis, "Analytical methods and rules of thumb for modelling DG - distribution interaction," in Proc. 2000 IEEE Power Engineering Society Summer Meeting, vo. 3, Seattle, WA, July 2000, pp. 1643 -1644.

[6] T Gozel , M H Hocaoglu, "An analytical method for the sizing and siting of distributed generators in radial systems," Electrical Power System Research 2009, 79 (6), pp. 912-18.

[7] M.M. Aman, G.B. Jasmon, H. Mokhlis and A.H.A. Bakar, "Optimal placement and sizing of a DG based on a new power stability index and line losses", Elsevier, Electrical Power \& Energy Systems, 43(2012), pp. 1296-1304.

[8] N Acharya, P Mahat and N Mithulananthan, "An analytical approach for DG allocation in primary distribution network," Electrical Power and Energy Systems 28(2006), pp.669-78.

[9] S Ghosh, SP Ghoshal and SA Ghosh, "Optimal sizing and placement of distributed generation in a network system," International Journal Electrical Power 2010, 32(8): pp.849-56.

[10] D.Q.Hung, N Mithulananthan and R.C. Bansal, “ Analytical Expressions for DG Allocation in Primary Distribution Networks,” IEEE Transaction on Energy Conversion, 25(2010), pp. 814-820.

[11] N.S. Rau and Y.H. Wan, "Optimum location of resources in distributed planning," IEEE Transaction in Power System 9(1994), pp. 2014-2020.

[12] M.H. Moradi and M. Abedini, "A combination of genetic algorithm nd particle swarm optimization for optimal DG location and sizing in istribution systems," Electrical Power and Energy Systems 34 (2012), pp. 66-74.

[13] A.A. Abou El-Ela, S.M. Allam and M.M. Shatla, "Maximal optimal benefits of distributed generation using genetic algorithms," Electrical Power System Research 80 (2010), pp. 869-77.

[14] S. Kansal, V Kumar and B. Tyagi, "Optimal placement of different type of DG Sources in distribution networks," Electrical Power and Energy Systems 53 (2013), pp. 752-760.

[15] D. Das, "Reactive power compensation for radial distribution networks using genetic algorithm," Electrical Power Energy System 24(2002), pp. 573-81. 